\title{
FILM “BIG BROTHER 2018” SEBAGAI INOVASI RELASI GURU DAN SISWA PERSPEKTIF PENDIDIKAN PEMBEBASAN PAULO FREIRE
}

\author{
Achmad Yulianto Widodo ${ }^{1}$, Alaika M. Bagus Kurnia ${ }^{2}$, \\ Anugerah Ilma Dinilillahi ${ }^{1}$, Moch. Wahyu Qodarullah ${ }^{1}$ \\ ${ }^{1}$ UIN Sunan Ampel, Surabaya, Indonesia \\ ${ }^{2}$ Institut Kesehatan dan Bisnis, Surabaya, Indonesia \\ *Corresponding Address: e01218001@uinsby.ac.id
}

Naskah diterima: 1 Oktober 2021 | Disetujui: 2 Januari 2022 | Diterbitkan: 22 Januari 2022

\begin{abstract}
This reaserch focuses on building the relationship between teachers and students in the film "Big Brother 2018" which shows the existence of liberation education. Using a descriptivequalitative research method that provides details regarding how to build relationships between teachers and students in a medium as an inspiration to be applied in schools. A qualitative approach by supporting data on content analysis is expected to produce writings that media such as films can be good examples of teacher-student relationships. The relationship between teacher and student in the film shows freedom in teaching at school. The theory used in this research is the concept of Pauolo Freire in the liberation of education which offers an educational model of conscientization, facing problems and humanization. So that it can be obtained 1) conscientization education that teaches critical of reality 2) dealing with problems that make school students not only memorize the contents of books so that they pass with good grades on exams, 3) humanization which illustrates that teachers also learn from their students or non-formal subjects. subjects.
\end{abstract}

Keywords: Teacher and student relations, 2018 film Big Brother, Paulo Freire, the concept of liberation.

\begin{abstract}
Abstrak: Penelitian ini terfokus pada pembangunan relasi antara guru dan siswa yang ada dalam film "Big Brother 2018" yang memperlihatkan adanya pendidikan pembebasan. Penelitian ini menggunakan metode penelitian deskriptif kualitatif yang menyajikan hal detail terkait cara membangun relasi antara guru dan siswa dalam sebuah media sebagai inspirasi untuk diterapkan di sekolah. Pendekatan kualitatif model analisis isi diharapkan dapat menghasilkan tulisan bahwa media film bisa menjadi contoh yang baik dalam hubungan guru dan siswa. Relasi guru dan siswa dalam film tersebut menunjukkan kebebasan dalam belajar di sekolah. Teori yang digunakan dalam penelitian ini adalah konsep Pauolo Freire dalam pembebasan pendidikan yang menawarkan model pendidikan konsientisasi, hadap masalah, dan humanisasi. Hasil penelitian ini menunjukkan bahwa, 1) pendidikan konsientisasi yang mengajarkan kritis terhadap realitas, 2) hadap masalah menjadikan siswa tidak hanya menghafal isi buku agar lulus dengan nilai bagus saat ujian, 3) humanisasi yang menggambarkan bahwa guru juga belajar dari siswanya atau subjek-subjek bukan subjek-objek.
\end{abstract}

Kata kunci: Relasi guru dan siswa, film Big Brother 2018, Paulo Freire, konsep pembebasan. 


\section{PENDAHULUAN}

Pendidikan merupakan sebuah pembelajaran yang dilakukan oleh banyak orang. Pendidikan merupakan sebuah penyanggah kesadaran dalam diri manusia, sedangkan media adalah sarana utama dalam revolusi pendidikan (Datungsolang, 2018). Media sebagai komunikasi dalam pengajaran untuk siswa yang efektif dalam membantu proses pembelajaran. Kebutuhan dalam pendidikan dengan media bisa mempermudah informasi atau pesan yang diberikan oleh guru kepada siswa (Umar, 2014). Di sisi lain, media seperti fim juga dapat memberikan inspirasi tersendiri bagi guru untuk melakukan pembaharuan dalam mendidik siswanya.

Melalui hal seperti film yang menginspirasi untuk melakukan pembaharuan dalam proses belajar mengajar, setidaknya dapat merubah suasana bosan pada proses pembelajaran. Dengan demikian guru bisa menjadi contoh dan tuntunan untuk siswa. Dalam proses belajar mengajar, harus ada timbal balik yang dilakukan oleh guru dan siswa. Guru tidak hanya mengajrakan ilmu tetapi juga nilai dan sikap (Suriadi, 2019). Seperti halnya dalam metamorfosis pengetahuan dan keterampilan dalam pendidikan secara umum. Perlu adanya peranan guru sebagai pembimbing untuk meningkatkan kualitas siswa. Siswa juga memiliki potensi untuk terus dikembangkan meskipun banyak problematika yang akan dilalui oleh siswa. Maka dari itu dibutuhkan interaksi yang solid terdahap kedua pemeran pendidikan dalam interaksi sosial (Ihsan, 2020).

Ktika proses pembelajaran monoton atau membosankan, maka sangat wajar jika siswa tidak memperhatikan. Hal tersebut akan menurunkan minat belajar siswa terhadap materi yang disampaikan oleh guru (Jayawardana, 2017). Kasus yang demikian membuat relasi sosial antara guru dan siswa menjadi renggang. Hal tersebut dikhawatirkan berdampak buruk pada timbal balik antara keduanya baik secara ilmu yang disampaikan, nilai, hingga perubahan sikap antara guru dan siswa. Guru yang memiliki keterampilan inovatif dalam belajar mengajar itu penting (Tahun, 2016).

Perlunya updrading dalam membangun relasi antara guru dan siswa sangat penting. Misalnya pada pelajaran matematika, pembelajan kontekstual pada pelajaran matematika lebih mudah dipahami sehingga berdampak pada ide imajinatif para siswa. Pada umumnya menyelesaikan soal matematika memerlukan rumus, sehingga hal itu dianggap sangat membosankan dan sulit untuk dipahami. Berbeda jika pembelajaran matematika dikaji dengan kontekstual atau diterapkan dalam kehidupan sehari-hari (Hutagaol, 2013). Peristiwa tersebut juga bagian dari inovasi dalam pembelajaran yang membentuk hubungan lebih erat antara guru dan siswa. Siswa mampu berimajinasi dan memahami dengan baik akan memberi dampak lebih pada guru terkait keberhasilan dalam mengajar. Ditambah banyak inspirasi dari berbagai media termasuk film untuk menambah kreatif dalam mengajar, belajar, dan berinteraksi di lingkungan sekolah. 
Melihat banyaknya perubahan yang terjadi saat pandemi Covid-19 sebenarnya sudah memberikan banyak ide cemerlang untuk para pendidik dalam berimajinasi demi menyukseskan belajar daring. Seperti penggunaan Google Classroom sebagai jalan untuk mempermudah pembelajaran. Namun, masalah fleksibilitas interaksi selama daring ini masih dianggap monoton (Herdiana, 2020). Walaupun banyak inovasi pembelajaran atau penyampaian materi melalui media sosial (TikTok, Instagram, Facebook, dan lain-lain) dengan kreativitas pada desain grafis. Bahkan film juga memberikan gambaran untuk menginspirasi pada proses pembelajaran. Seperti halnya yang terjadi dalam film "Big Brother 2018" yang di dalamnya ada berbagai cara dan ide bagaimana guru mendekati siswanya dengan menyamakan pemikiran agar siswa bisa patuh. Melalui film dapat menginspirasi pendidikan untuk melakukan tindakan yang membangun hubungan baik dalam lingkungan sekolah. Dalam menjalin buhungan yang baik itu, Paulo Freire menawarkan pendidikan pembebasan dengan tiga konsep utama yaitu konsientisasi, humanisasi, dan hadap masalah.

Ketiga konsep tersebut membantu dalam pembangunan relasi guru dan siswa. Dimulai dengan Paulo Freire berpendapat terkait menjalin hubungan guru dan siswa penting dengan adanya dialog yang baik. Dialog juga merupakan hal yang cukup sensitif dalam membangun relasi antara guru dan siswa. Dialog itulah yang nantinya akan menuntun para pendidik untuk membentuk sikap saling menghargai, sama-sama belajar, dan mengkikis hal seperti penguasaan (Sesfao, 2020), atau anggapan bahwa guru selalu benar oleh para siswa. Dialog yang dimaksudkan adalah dialog yang konsepnya untuk aktor pendidikan agar sadar tentang realitas sosial (Abdillah, 2017). Seperti hanya dalam film "Big Brother" yang menampilkan rangkaian cara para actor pendidikan dalam membangun relasi yang baik, serta membentuk susana pembelajaran agar berkembang dengan baik melalui dialog secara interaktif oleh para aktor pendidikan (Abrams, 2018).

Dalam pendidikan pembebasan tentang konsep humanisasi di mana dalam konsep ini Paulo Freire ingin menebas adanya proyeksi pendidikan yang melanggar Hak Asasi Manusia (HAM). Kurangnya relasi yang baik antar aktor pendidikan membuat banyak praktek pendidikan yang dehumanisasi, sehingga anggapan tentang subjek yang berhadapan dengan subjek itu dianggap kurang dan masih beranggapan bahwa subjek berhadapa dengan objek. Hubungan subjek dengan objek inilah yang kurang sehat untuk lingkungan pendidikan dalam membangun hubungan antar aktor pendidikan. Hal yang diinginkan oleh Paulo Freire adalah hubungan yang terfokus pada subjek dengan subjek (Datunsolang, 2017). Membangun hubungan yang baik itu perlu memahami tentang kemanusiaan. Dalam film "Big Brother 2018" lebih menekankan rasa saling mengerti mengenai konsep humanisasi. Hingga rela berkorban demi menyelamatkan pendidikan dan hubungan yang baik antar aktor (Rosikin, 2020). 
FILM “BIG BROTHER 2018" SEBAGAI INOVASI RELASI GURU DAN SISWA PERSPEKTIF ...

Achmad Yulianto Widodo, Alaika M. Bagus Kurnia, Anugerah Ilma Dinilillahi, Moch. Wahyu Qodarullah

Konsep hadap masalah dalam pendidikan dapat terjadi kapanpun dan di manapun asalkan para aktor pendidikan masih berstatus hidup. Konsep ini melibatkan kesadaran diri dari seorang subjek sebagai tokoh yang berperan dalam aksi pembebasan (Syaikhudin, 2012). Walaupun pada dasarnya masalah tidak hanya dalam dunia pendidikan, namun hal itu berimbas pada dehumanisasi. Maka dari itu perlu belajar membantu menangani masalah sosial yang terjadi antar aktor pendidikan untuk terus menumbuhkan relasi yang baik antar aktor (Abrams, 2018).

\section{METODE}

Penelitian ini menggunakan metode deskriptif kualitatif. Penelitian ini juga menggambarkan objek kajian sesuai dengan fakta yang tersedia di lapangan (Sartika, 2014). Penelitian ini menjelaskan data sesuai dengan teori yang akan digunakan, yaitu teori pendidikan pembebasan dari Paulo Freire. Analisis data dilakukan dengan metode analisis isi untuk memeriksa komponen-komponen pesan komunikasi (messages). Teknik pengumpulan data dalam film "Big Brother 2018" diperoleh melalui dokumentasi unggahan film salah satu chanel Youtube dan scene yang diambil sesuai pada fokus teori yang akan digunakan.

Fokus penelitian ini adalah seluruh scene film "Big Brother 2018" yang berkaitan dengan teori pembebasan pendidikan Paulo Freire yang nantinya dapat dijadikan inspirasi untuk membangun relasi antara guru dan siswa. Guna mempermudah penelitian, maka penulis menetapkan kategori yang harus memiliki berupa scene film "Big Brother 2018" secara keseluruhan. Pertama, konsientisasi dalam pendidikan yang menjelaskan bagian dialog interaktif yang dilakukan aktor pendidikan dalam film "Big Brother 2018". Kedua, humanisasi dalam pendidikan yang menerangkan tentang pentingnya menjunjung humanisme dalam pendidikan yang diperankan aktor pendidikan dalam film "Big Brother 2018". Ketiga, hadap masalah dalam pendidikan yang memaparkan tentang rumitnya masalah dan penyelesaian masalah yang dihadapi oleh para aktor dalam film "Big Brother 2018".

\section{HASIL DAN PEMBAHASAN}

Film yang dibintangi oleh Donnie Yen (Yen, n.d.), seorang praktisi Wu Shu ("Donnie Yen Biography," n.d.) ini memberikan banyak sekali inspirasi yang terbilang sederhana dan tidak terduga. Film "Big Brother 2018" merupakan sebuah film yang memiliki genre drama dan aksi. Film ini diproduksi di negara Hongkong dan dilantunkan dengan bahasa Cantonese. Film yang telah didirektori oleh Kam Ka-Wai dan diproduksi Wong Jing beserta kawannya ini memiliki judul asli “Daai Si Hing”. Hingga akhirnya film ini diproduksi oleh beberapa perusahaan salah satunya Mega- 
Vision Project Workshop yang juga mendistribusikan film tersebut ("Big Brother (2018 Film)," 2021).

Setelah tim penulis melakukan observasi atas dokumentasi film "Big Brother 2018" ini yang dijumpai dalam salah satu postingan chanel Youtube Ig Chanel (lg channel, 2021) maka ditemukan banyak adegan terkait dengan ketiga penetapan kategori. Penetapan kategori berupa konsientisasi dalam pendidikan, humanisasi dalam pendidikan, dan hadap masalah dalam pendidikan.

Pertama, konsientisasi dalam pendidikan ditemukan dalam adegan menit ke 11:26-1425. Guru Chen yang mengajar siswanya untuk melihat satu hal ke berbagai arah. Adegan menit 18:59-22:00 guru Chen mempelajari 5 siswa bermasalah melalui cv siswa. Menit ke 27:40-28:47, guru Chen mengajarkan Xiang Zufa untuk percaya diri di panggung dengan meberikan contoh. Menit ke 32:0332:35, guru Chen yang mengajarkan tentang tata tertib berkendara di Hong Kong dan mengajak Wang Denan ke arena permainan balap mobil. Menit ke 60:00-60:55, diperlihatkan adanya keaktifan dialog dalam kelas guru Chen. Dari sini maka didapati total adegan yang menggambarkan tentang konsientisasi dalam pendidikan di film "Big Brother 2018" ada 5 adegan dari keseluruhan adegan film dengan durasi 88:33.

Kedua, humanisasi dalam pendidikan ditemukan dalam adegan menit ke 16:44-18-17, saat guru Chen melerai 5 siswa bermasalah dan diancam dikeluarkan tapi memperjuangkan mereka tetap sekolah. Adegan Menit ke 20:00-22:30 yaitu perdebatan guru Chen dengan kepala sekolah untuk mempertahankan siswa-siswanya di sekolah. Menit ke 33:39-36:51, cara guru Chen memabantu Wang Denan meneyelesaikan konflik keluarga dengan ayahnya yang pilih kasih. Menit ke 37:2637:31, guru Chen merencanakan dan membantu ayah siswa kembar untuk berhenti minum-minuman keras. Menit ke 42:08-44:28, guru Chen bertemu nenek Li Weicong dan memberi Li Wei Chong dana pendidikan, karena neneknya hanya mengetahui bahwa dirinya anak baik dan pintar. Menit ke 49:5850:52, guru Chen yang telah menjamin Li Weicong dari polisi karena terbukti tidak bersalah atas kejadian di tempat tinju. Menit ke 53:26-54:36, diperlihatkan bahwa guru Chen juga sumber masalah di sekolah tetapi guru Chen oleh kepala sekolah dipindahkan ke sekolah militer di Amerika dan kepala sekolah memaafkan kejadian saat ada acara di sekolah. Dari sini maka didapati total adegan yang menggambarkan tentang humanisasi dalam pendidikan di film "Big Brother 2018" ada 7 adegan dari keseluruhan adegan film dengan durasi 88:33.

Ketiga, hadap masalah dalam pendidikan didapati dalam adegan menit ke 05:14-07:21 saat guru Chen masuk kelas menghadapi siswa-siswa bandel. Adegan menit ke 26:50-28:47, cara guru Chen membantu menyelesaikan masalah siswa bernama Xiang Zufa. Menit ke 29:59-30:14, guru Chen bicara baik-baik terkait anaknya pak Guan untuk membantu 2 siswa kembarnya menyelesaikan 
FILM “BIG BROTHER 2018" SEBAGAI INOVASI RELASI GURU DAN SISWA PERSPEKTIF ...

Achmad Yulianto Widodo, Alaika M. Bagus Kurnia, Anugerah Ilma Dinilillahi, Moch. Wahyu Qodarullah

konflik dengan ayahnya. Menit ke 33:39-36:51, guru Chen membantu Wang Denan menyelesaikan masalah dan mendapat izin ayahnya untuk terus belajar. Menit ke 37:26-40:01, pelajaran di pusat rehabbilitasi untuk menyelesaikan masalah siswa kembar guru Chen. Menit ke 45:59-50:59, guru Chen mendatangi Li Weicong untuk membantunya menyelesaikan masalah di tempat tinju dan mengajaknya terus bersekolah. Dari sini maka didapati total adegan yang menggambarkan tentang hadap masalah dalam pendidikan di film "Big Brother 2018" ada 6 adegan dari keseluruhan adegan film dengan durasi 88:33.

\section{Inovasi Membangun Relasi antara Guru dan Siswa melalui Film "Big Brother 2018" dengan Pendidikan Pembebasan Paulo Freire}

Dari data yang telah disajikan di atas, maka perlu direfleksikan dengan teori pembebasan dari Paulo Freire. Seperti yang telah dituliskan sebelumnya bahwa ada tiga poin penting dalam pendidikan pembebasan Paulo Freire yaitu konsientisasi, humanisasi, dan hadap masalah. Sementara itu dari film "Big Brother 2018” penulis telah mengetahui jumlah adegan dan sudah mengklasifikasikan sesuai dengan poin teori pendidikan pembebasan Paulo Freire, sehingga perlu analisis lebih lanjut untuk mencapai tujuan yang diharapkan.

Konsientisasi menurut Freire merupakan suatu proses penyadaran yang mengarah pada konsep pembebasan yang dinamis dan mendorong pada penciptaan manusia yang lebih utuh. Konsientisasi dapat dipahami sebagai suatu gambaran tingkat kesadaran di mana setiap individu mampu melihat sistem sosial secara kritis (Datungsolang, 2018). Dalam konsep ini menempatkan manusia sebagai subjek dalam kehidupan, dengan begitu sesuai dengan keinginan dan kreatifvitasnya, bukan sebagai objek atau selalu menerima perlakuan dari orang lain. Dengan demikian manusia mampu hidup sesuai dengan kodratnya yaitu manusia yang merdeka. Subjektivitas dan objektivitas merupakan dasar untuk mendapatkan pengetahuan tentang dunia yang empiris dan realistis. Pengetahuan ini bukan hanya sekadar sesuatu yang berdasarkan keadaan yang konkrit manusia yang bisa dilihat, tetapi juga termasuk bagaimana manusia memandang dirinya dan realitas kehidupan.

Dalam hal itu Freire menentang sistem pendidikan yang pasif dan tidak berkembang. Dalam dunia pendidikan sangat kental dengan nuansa penindasan, sehingga Freire merasakan ketidakefektivan menjalankan pendidikan. Sistem pendidikan inilah yang disebut dengan pendidikan gaya bank, yaitu guru seakan-akan menjadi seorang yang memiliki uang yang banyak yang disimpan di bank. Sedangkan siswa dijadikan sebagai bank, yaitu menampung seluruh informasi. Sehingga Freire mempertentangkan pendidikan dengan sistem pendidikan otoriter yang diistilahkan dengan "banking education". Pendidikan banking memisahkan pelajar dari konten dan proses belajar 
mengajar. Hal itu menjadikan ilmu pengetahuan seakan-akan barang yang bisa dipindah-pindah dari satu tempat ke tempat lain.

Bagi Paulo Freire, pendidikan gaya bank ini merupakan warisan kolonial, di mana pendidikan dibuat demi memenuhi kaum penguasa. Dengan demikian dapat menghasilkan peserta didik yang akan mewarisi dan bergerak sesuai dengan kepentingan kaum penindas bahkan kepada penguasa. Pendidikan gaya bank ini dikritik sebagai bentuk dehumanisasi (Rohinah, 2019).

Pendidikan gaya bank ditolak secara menyeluruh oleh Freire. Freire mengganti dengan sebuah konsep tentang manusia sebagai mahluk yang sadar, dan kesadaran sebagai kesadaran yang diarahkan ke dunia. Freire menawarkan sebuah konsep kekebasan atau "problem pasing education" yang berlandarkan pada keterkaitan demokrasi guru dan siswa. Ia juga mengusulkan suatu "partnership" antara guru dan siswa saling interaksi (Prastowo, 2020).

Dalam film "Big Brother 2018" dapat diketahui bahwa keaktifan berdialog di kelas guna meningkatkan suasana belajar yang tidak membosankan. Dalam data tersebut ditemukan pada adegan menit ke 11:26-1425, guru Chen yang mengajar siswanya untuk melihat satu hal ke berbagai arah. Diartikan bahwa guru dituntut untuk kreatif dalam berdialog dan mencari topik dialog. Satu topik yang dapat membuat pengetahuan dasar para siswa sehingga pengetahuan siswa tidak terbatas yang ada dalam buku pelajaran. Selain itu, guru akan lebih dikenal ketika dirinya kreatif dalam memilih topik pelajaran dan berwawasan luas. Kemudian penafsiran pada adegan menit ke 18:59-22:00 guru Chen mempelajari 5 siswa bermasalah melalui cv siswa. Mengangap siswa sebagai subjek bukan objek, selain berdialog juga butuh pendekatan agar lebih mudah dalam menanggapi kebutuhan dan keinginan siswa. Menit ke 27:40-28:47, guru Chen mengajarkan Xiang Zufa untuk percaya diri di panggung dengan meberikan contoh. Di mana dalam konsientisasi yang dijelaskan di atas bahwa siswa juga subjek, sehingga butuh kepercayaan diri untuk menghadapi subjek yang akan diajar agar subjek yang diajar atau siswa dapat mengikuti arahan gurunya.

Menit ke 32:03-32:35, guru Chen yang mengajarkan tentang tata tertib berkendara di Hong Kong dan mengajak Wang Denan ke arena permainan balap mobil. Sama halnya dengan penafsiran sebelumnya bahwa butuh kekuatan untuk menghadapi siswa sebagai subjek. Kekuatan untuk memberikan pengertian tanpa harus memberikan tekanan atau penindasan terhadap siswa. Menit ke 60:00-60:55, diperlihatkan adanya keaktifan dialog dalam kelas guru Chen. Cara mengajar yang tidak membosankan dan siswa bisa tetap aktif dari film tersebut adalah bermain tebak-menebak. Membangun dialog yang menyenangkan di kelas itu perlu agar para pelajar tidak mearasa bahwa pembelajaran hanya membuang waktu. Dari hal-hal seperti ini rupanya mendapat dukungan dari Paulo Freire untuk menebas pendidikan yang mengekang seperti gaya bank. Bagi Paulo Freire 
konsientisasi merupakan proses seseorang dalam mewujudkan diri yang sadar secara utuh. Selain itu, manusia hadir untuk saling memahami, menyadari, dan mengetahui realitas sosial hingga akhirnya dapat mengubah yang telah terjadi (Ajat \& Hambali, 2021). Hal ini sangat menarik dan mampu menjadi inspirasi untuk berinovasi menciptakan relasi yang baik antara guru dan siswa baik di lingkungan sekolah maupun di luar sekolah.

Manusia dituntut untuk sadar akan realitas, maka Paulo Freire mengungkapkan tentang kesadaran berdasarkan konteks kebebasan dan kemanusian. Paulo Freire membagi kesadaran menjadi 3 bagian sesuai dengan konteks itu. Pertama, kesadaran magis (Magical Consciousness), dalam hal ini kesadaran masuk tahap di mana manusia tidak mampu mengetahui kelemahannya, sehingga menyebabkan faktor kemunduran kualitas. Kedua, kesadaran naif di mana kesadaran lebih melihat aspek manusia merupakan sumber permasalahan dalam masyarakat. Dalam kesadaran ini ada penentu perubahan sosial berupa masalah kesadaran etika dan kreativitas. Ketiga, kesadaran kritis. Dalam kesadaran ini lebih menekankan pada aspek sistem dan struktur sebagai sumber masalah. Pendidikan mencoba menganalisis secara kritis sistem dan struktur sosial, politik, ekonomi, budaya, dan konteks masyarakat lainnya. Hal itu akan melatih siswa agar mengidentifikasi dirinya dalam sistem dan struktur yang ada, menganalisis bagaimana sistem itu, serta bagaimana mentransformasikannya. Tugas pendidikan dalam paradigma ini adalah menciptakan ruang dan kesempatan agar siswa terlibat aktif dalam proses penciptaan struktur secara fundamental byang lebih baik (Prastowo, 2020).

Poin kedua tentang humanisasi dalam pendidikan di mana Paulo Freire ini menjunjung tinggi Hak Asasi Manusia (HAM) dalam dunia pendidikan. Bagi Paulo Freire proses pendidikan ini merupakan suatu proses yang tidak mengekang atau bisa disebut membebasakan. Dalam dunia pendidikan tidak ada subjek yang punya peranan tinggi untuk membebaskan objek dari belenggu kebodohan. Pendidikan menuntun para aktor pendidikan untuk kritis terhadap realitas. Jadi, bisa dikatakan bahwa posisi dari para aktor pendidikan adalah sahabat agar hubungan yang baik bisa terjalin dan mengkikis pelanggaran Hak Asasi Manusia sesamanya (Sholehuddin, 2018).

Sama halnya dalam adegan menit ke 16:44-18-17, saat guru Chen melerai 5 siswa bermasalah dan diancam dikeluarkan tapi memperjuangkan mereka tetap sekolah. Posisi ini seorang pengajar memiliki wewenang untuk melindungi siswanya dan menghargai keberadaan siswanya sebagai manusia. Walaupun memerlukan perjuangan dan pengorbanan tetapi untuk menjadi peserta didik itu juga bagian dari Hak Asasi Manusia. Maka tidak heran jika di film tersebut guru rela membela siswa yang bermasalah agar tidak di keluarkan dari sekolah. Pada adegan menit ke 20:00-22:30, perdebatan guru Chen dengan kepala sekolah untuk mempertahankan siswa-siswanya di sekolah. Adegan ini berisi perjuangan guru untuk terus berusaha menyadarkan kepala sekolah bahwa sekolah itu tempat 
untuk menumbuhkan humanisasi bukan tempat untuk membentuk objek agar mendapat penghargaan. Disusul pada menit 33:39-36:51, cara guru Chen memabantu Wang Denan meneyelesaikan konflik keluarga dengan ayahnya yang pilih kasih. Sikap humanisme itu harus ada pada setiap orang di manapun tempatnya dan kapanpun waktunya. Dari adegan ini dapat didefinisikan bahwa seorang guru memiliki kuasa untuk membantu menyelesaikan masalah melalui pendekatan yang tidak menyakiti siswanya.

Menit ke 37:26-37:31, guru Chen merencanakan dan membantu ayah siswa kembar untuk berhenti minum-minuman keras. Pada adegan ini seorang guru bukan menyalahkan orang lain yang membuat siswanya menjadi nakal, melainkan membantu dan memberikan solusi agar orang lain (yang menyebabkan siswa menjadi nakal) itu sadar akan sebenarnya kesalahan dan sadar tentang kenyataan yang seharusnya benar-benar dilihat. Menit ke 42:08-44:28, guru Chen bertemu nenek Li Weicong dan memberi Li Wei Chong dana pendidikan, karena neneknya hanya mengetahui bahwa dirinya anak baik dan pintar. Seorang guru itu harus mampu berkorban dan menjaga rahasia siswa. Di samping dirinya harus menghadapi sikap siswa yang begitu brutal. Menit ke 49:58-50:52, guru Chen yang telah menjamin Li Weicong dari polisi karena terbukti tidak bersalah atas kejadian di tempat tinju. Sama halnya seperti sebelumnya, seorang guru dalam masalah humanisasi bukan malah merendahkan siswanya tetapi malah harus membantu atau menjadi pelindung dalam keadaan tertentu. Menit ke 53:26-54:36, diperlihatkan bahwa dulu guru Chen juga sumber masalah di sekolah tetapi guru Chen oleh kepala sekolah dipindahkan ke sekolah militer di Amerika dan kepala sekolah memaafkan kejadian saat ada acara di sekolah. Dari sini dapat ditafsirkan bahwa yang namanya pendidik tidak bisa lepas dari pandangan hak asasi manusia. Menghargai bahwa seorng siswa masih memiliki hak untuk belajar dan berprestasi walaupun dirinya sering membuat masalah yang besar.

Teori humanisasi Paulo Freire sangat berperan. Selain untuk membaca adegan film juga menjadi inspirasi untuk para aktor pendidikan bertumpu pada humanisme. Adegan-adegan tentang humanisasi itu juga mendapat dukungan dari Paulo Freire. Dari beberapa aspek dalam humanistik pendidikan Nimrod Aloni yang merujuk kepada tokoh-tokoh pendidikan termasuk Paulo Freire, menyampaikan setidaknya ada lima aspek. Lima aspek tersebut adalah pendekatan holistik kepada siswa, hubungan antara pribadi yang tulus, iklim sosial keamanan dan toleransi, iklim intelektual yang bebas dan kaya budaya, dan metode pengajaran bermakna (Aloni, 2013). Kelima hal demikian yang akan mendukung jalannya relasi baik, sehingga seluruh penindasan baik dalam dunia pendidikan maupun lainnya di dunia ini dapat dihapuskan (Abdillah, 2017).

Dalam masalah pendidikan guru juga seorang yang harus dituntut untuk bangga atas potensi siswanya. Seperti halnya yang dicontohkan dalam film tersebut bahwa guru yang secara manusiawi 
mempertahankan siswanya karena sudah paham potensi apa yang dimiliki siswanya. Maka dibutuhkan daya untuk mengkritisi dan berpartisipasi dalam jiwa dan talenta siswa (Mualim, 2017). Paulo Freire juga berpandangan bahwa maraknya dehumanisasi akibat dari sistem yang tidak adil (Zaini, 2014). Akibatnya, banyak masyarakat yang tertindas. Paulo Freire mengatakan bahwa mereka tidak menyadari akan ketertindasannya, karena masih berada dalam kondisi kesadaran magis (tidak mampu mengetahui kelemahannya). Dengan begitu, Freire mencoba membangkitkan kesadaran akan ketertindasan, dengan mengusulkan metode melalui dialog. Freire menekankan bahwa dialog tersebut tidak hanya sebatas mengupas materi pembahasan hingga tuntas dan mendasar, namun menekankan prinsip-prinsp humanisme. Metode dialog Freire menjadi pintu masuk menuju pembebasan, di mana adanya tempat untuk saling menghargai sebagai sesama manusia, membahas topik-topik yang nyata dan aktual di sekelilingnya sembari belajar menuliskannya. Kemampuan untuk menulis dengan benar itu baik, namun lebih ditekankan pada makna dan konsep pemikiran yang terbangun (Abdillah, 2017). Maka dapat dicontoh melalui film "Big Brother 2018” ini terkait muri-siswa pada kelas yang tidak mendapat perlakuan baik tetapi memiliki guru yang menjunjung tinggi humanisme agar tidak terus menerus buta realitas dan mudah ditindas. Cara menyelesaikan masalah realitas sosial dalam film "Big Brother 2018" ini dapat dilihat bahwa penyelesaiannya tidak semua dengan kekerasan melainkan dengan dialog.

Dialog antar manusia harus bedasarkan atas kepekaan terhadap kemampuan bawaan untuk menemukan diri sendiri. Dialog mengandaikan kerendahan hati, yaitu kemauan belajar dari orang lain meskipun menurut perasaan kebudayaan dianggap lebih rendah, memperlakukan orang lain sederajat, keyakinan bahwa orang lain mampu mengajar dan membimbing. Dialog menuntut keparcayaan yang besar bahwa manusia pada hakikatnya dipanggil untuk menjadi subjek yang harus mengubah dunia. Dialog menuntut sikap mau mendengar dan memahami diri sendiri bahwa manusia sebagai makhluk yang belum selesai (Rohinah, 2019).

Dalam hubungan guru dengan siswa telah disampaikan oleh Freire ketika mengemukakan kritik tajam atas konsep pendidikan gaya bank. Konsep gaya bank melahirkan suatu kontradiksi dalam hubungan guru dengan siswa., bahkan lebih dari itu. Konsep pendidikan gaya bank juga memelihara dan mempertajam, sehingga mengakibatkan terjadinya kebekuan berfikir dan tidak munculnya kesadaran kritis pada diri siswa.

Poin ketiga ini tentang hadap masalah di mana bagi Paulo Freire hadap masalah dituntut untuk memahami secara kritis akan keberadaan manusia di dunia. Manusia dalam memandang dunia ini bukanlah suatu yang statis melainkan suatu proses, Sehingga pendidikan posisinya sebagai praksis pembebasan yang bersifat manusiawi. Melalui anggapan dasar bahwa manusia itu adalah makhluk 
yang posisinya sebagai korban penindasan sehingga harus berjuang untuk membebasakan diri dari penindasan (Junaedi, 2018).

Dalam film "Big Brother 2018” sendiri didapati beberapa adegan tentang hadap masalah dalam pendidikan. Pada menit ke 05:14-07:21 saat guru Chen masuk kelas dan menghadapi siswa-siswa bandel. Di mana adegan ini dilakukan saat mengatasi atau guru sedang berusaha untuk menyadarkan para siswa yang tidak memperhatikan sang guru. Dalam menghadapi siswanya guru memberikan pengertian bahwa sudah masuk waktu belajar dengan melakukan hal-hal unik tanpa menggunakan kekerasan, sehingga siswa bisa sadar akan keberadaan dirinya sendiri dan gurunya. Adegan menit ke 26:50-28:47, cara guru Chen membantu menyelesaikan masalah siswa bernama Xiang Zufa. Memberikan pengertian agar keluar dari ketidaksadaran bahwa diri siswa itu tidak mampu untuk mencapai cita-cita. Dengan memberikan contoh dan menemani siswa untuk memulai cita-citanya itu adalah peran guru. Tidak hanya menuntut dan menyuruh tanpa ikut berpartisipasi. Seperti yang ditunjukkan Paulo Freire dalam malasah humanisasi. Menit ke 29:59-30:14, guru Chen bicara baikbaik terkait anaknya Pak Guan untuk membantu 2 siswa kembarnya menyelesaikan konflik dengan ayahnya. Membuka ruang kesadaran manusia agar keluar dari ketidaksadarannya, sehingga perlu dialog bukan kekerasan. Dengan begitu seseorang akan mengerti dan sadar akan posisi dirinya sendiri. Menit ke 33:39-36:51, guru Chen membantu Wang Denan menyelesaikan masalah dan mendapat izin ayahnya untuk terus belajar. Memberikan pengertian dan membantu seseorang keluar dari kesadaran itu belum tentu berhasil hanya dengan dialog tetapi juga butuh tindakan yang membuktikan bahwa seseorang yang sedang ditindas itu mampu mempertahankan apa yang harus dirinya pertahankan.

Menit ke 37:26-40:01, pelajaran di pusat rehabbilitasi untuk menyelesaikan masalah siswa kembar guru Chen. Banyak cara untuk memberikan pengertian akan kesadaran bahwa sebenarnya dirinya mampu melakukan hal yang harus dilakukan. Seorang guru dituntut untuk memahami keadaan demikian agar dapat memberikan solusi terbaik terhadap masalah yang dihadapi siswanya dan menunjukkan realitas sosial sesungguhnya. Menit ke 45:59-50:59, guru Chen mendatangi Li Weicong untuk membantunya menyelesaikan masalah di tempat tinju dan mengajaknya terus bersekolah. Walaupun setiap siswa memiliki masalah yang berbeda tetapi pada dasaranya mereka sama masih kurang mampu untuk mengidentifikasi kelemahannya agar bisa terus maju berkarya dengan cita-cita dan kelebihannya. Seorang guru selain dituntut untuk memandang siswa sebagai subjek juga dituntut untuk menuntun siswa agar memiliki rasa kritis terhadap kehidupan.

Hadap masalah dalam pendidikan selain mmeberikan kesadaran secara kritis juga menjadikan hubungan yang horizontal antara aktor pendidikan (Ayudha, 2016). Dari film itu juga dapat diketahui 
FILM “BIG BROTHER 2018" SEBAGAI INOVASI RELASI GURU DAN SISWA PERSPEKTIF ... Achmad Yulianto Widodo, Alaika M. Bagus Kurnia, Anugerah Ilma Dinilillahi, Moch. Wahyu Qodarullah

bahwa menganggap bodoh orang lain secara mutlak itu juga bagian dari penindasan (Fadli, 2020). Maka dari itu seorang guru perlu memberi ruang agar para siswanya mampu dan tidak diremehkan. Menanggapi hal ini maka hadap masalah dalam pendidikan perlu adanya dialog sebagai pengungkap realitas yang terjadi, sehingga selama pelaksanaannya akan tercipta harapan yang tidak sia-sia karena kurang kritis antar aktor pendidikan (Fadli, 2020).

Cara seorang guru menanggapi masalah yang terjadi pada siswanya pada film tersebut justru berusaha membebaskan siswa dari belenggu yang membuat meraka terjerat. Berdasarkan pemikiran Paulo Freire hadap masalah dalam dunia pendidikan harusnya memberikan keleluasaan untuk mencaari dan menggali serta menemukan pengetahuan sesuai dengan realitas (Manullang et al., 2021). Sementara dari hasil penelitian juga diketahui bahwa seorang guru yang membantu mencari solusi untuk siswa-siswanya dan menemukan jalan keluar dari masalah yang sedang dihadapi dengan cara yang mengejutkan. Sesuai dengan yang disampaikan Paulo Freire bahwa siswa diajak untuk melakukan pengamatan terhadap kenyataan disekitarnya dan diberi kebebasan dalam berpikir juga berusaha mencari tahu akan sebab juga akibat dari kenyataan dan problematika hidup murd (Manullang et al., 2021).

Hadap masalah dalam pendidikan bukan sebuah hal yang perlu dikawatirkan. Namun, lebih baik diterapkan dalam dunia pendidikan.karena metode ini bukan metode yang membelenggu dan menindas para siswa. Justu akan menyadarkan siswa-siswa agar memahami kenyataaan hidup dan masalah yang dihadapi. Lebih lagi Paulo Freire ini menganggap bahwa guru memiliki posisi yang sejajar dengan siswa, sehingga bisa dengan mudah terjadi dialog (Putra, 2021). Dengan demikian hubungan antara guru dan siswa dapat terjalin dengan mudah dan bukan sebuah hal yang sukar lagi untuk siswa menanyakan solusi atas permasalahn yang dihadapi.

Dari hasil penelitian ini, film "Big Brother 2018" dapat memberikan inovasi terhadap para aktor pendidikan untuk membangun relasi yang baik. Melalui berbagai hal tanpa harus melakukan hal seperti dehumanisasi. Dengan begitu film ini mampu memberikan inspirasi untuk melakukan hal yang sama. Namun tidak keluar dari prinsip pendidikan pembebasan yang ditawarkan oleh Paulo Freire. Di mana pada setiap prinsip baik konsientisasi, humanisasi, dan hadap masalah mengutamakan dialog bukan anti dialog. Anti dialog yang mana posisi guru hanya meberikan materi-materi saja tanpa mendengarkan jawaban atau reaksi dari siswa (Tara, 2016).

Menurut Paulo Freire idealnya pendidikan adalah saat adanya penjelasan secara diagonal antara guru dan siswa. Di mana posisi itu terjadi antara guru sebagai siswa dan siswa sebagai guru, sehingga berbeda jauh hasil akhirnya dengan prinsip gurunya siswa dengan siswanya guru (Tara, 2016). Maka 
tidak heran apabila selama ini ada kesalahan posisi dan membuat hubungan antara guru dan siswa menjadi renggang.

\section{KESIMPULAN}

Memabangun relasi antara guru dan siswa dengan baik diperlukan usaha dan pengorbanan. Membangun relasi antara guru dan siswa juga membutuhkan pedoman seperti prinsip konsirntisasi, humanisasi, dan hadap masalah. Dalam ruang lingkup pendidikan perlu adanya hubungan baik agar mencapai tujuan yang baik. Solusi yang menginspirasi telah ditawarkan oleh film "Big Brother 2018" terkait cara untuk menjalin hubungan baik dengan siswa-siswa bermasalah. Dari film tersebut juga dapat membuka ruang bahwa sebagai aktor pendidikan perlu saling belajar. Guru belajar dari siswa dan siswa belajar dari guru, sehingga ada ikatan anatara keduanya saat menghadapi permasalahan. Jadi, media seperti film pun dapat menginovasi para aktor pendidikan walaupun tidak lepas dari prinsip konsientisasi, humanisasi, dan hadap masalah untuk mewujudkan hubungan baik antara guru dan siswa dalam lingkungan sekolah. Dengan demikian membangun relasi antara guru dan siswa itu sangat penting.

\section{DAFTAR PUSTAKA}

Abdillah, R. (2017). Analisis Teori Dehumanisasi Pendidikan Paulo Freire. Jurnal Aqidah dan Filsafat Islam, 2(1), 21.

Abrams, S. (2018, August 31). Big Brother [..Com]. Rogerebert. https://www.rogerebert.com/reviews/bigbrother-2018

Ajat, A. S., \& Hambali, R. Y. A. (2021). Analisis Filsafat Paulo Freire Terhadap Sistem Pendidikan Indonesia. Jurnal Perspektif, 5(1), 14-32.

Aloni, N. (2013). Empowering dialogues in humanistic education. Educational Philosophy and Theory, 45(10), 1067-1081. https://doi.org/10.1111/j.1469-5812.2011.00789.x

Asri, R. (2020). Membaca Film Sebagai Sebuah Teks: Analisis Isi Film "Nanti Kita Cerita Tentang Hari Ini (NKCTHI).” Jurnal Al Azhar Indonesia Seri Ilmu Sosial, 1(2), 74-86.

Ayudha, N. (2016). Manifestasi Pendidikan Kritis (Pendidikan Hadap Masalah Sekolah Alternatif Qaryah Thayyibah di Salatiga). Jurnal Sosiologi Pendidikan Humanis, 1(2), 173-182. https://doi.org/10.17977/um021v1i22016p173

Big Brother (2018 film). (2021, October 19). [..Org]. Wikipedia. https://en.wikipedia.org/wiki/Big_Brother_(2018_film) 
FILM “BIG BROTHER 2018" SEBAGAI INOVASI RELASI GURU DAN SISWA PERSPEKTIF ...

Achmad Yulianto Widodo, Alaika M. Bagus Kurnia, Anugerah Ilma Dinilillahi, Moch. Wahyu Qodarullah

Datungsolang, R. (2018). Konsep Pendidikan Pembebasan dalam Perspektif Islam (Studi Pemikiran Paulo Freire). Jurnal Ilmiah AL-Jauhari: Jurnal Studi Islam dan Interdisipliner, 3(1), 49-77. https://doi.org/10.30603/jiaj.v3i1.686

Datunsolang, R. (2017). Konsep Pendidikan Pembebasan Dalam Perspektif Islam (Studi Pemikiran Paulo Freire). Tadbir: Jurnal Manajemen Pendidikan Islam, 5(1), 132-146.

Fadli, R. V. (2020). Tinjauan Filsafat Humanisme: Studi Pemikiran Paulo Freire dalam Pendidikan. Reforma: Jurnal Pendidikan Dan Pembelajaran, 9(2), 96-103.

Herdiana, D. (2020). Inovasi Proses Pembelajaran Daring Bagi Mahasiswa Kelas Karyawan di Masa Pandemi Covid-19. Konferensi Nasional Pendidikan I, 9.

Hutagaol, K. (2013). Pembelajaran Kontekstual Untuk Meningkatkan Kemampuan Representasi Matematis Siswa Sekolah Menengah Pertama. Infinity Journal, 2(1), 85-99. https://doi.org/10.22460/infinity.v2i1.27

Ihsan, F. (2020). Sociology Short Movie: Kerjasama Konkret Dan Pendorong Minat Belajar. Civics Education And Social Science Journal (CESSJ), 2(1).

Jayawardana, H. B. A. (2017). Paradigma pembelajaran biologi di era digital. Jurnal Bioedukatika, 5(1), 1217.

Junaedi, R. A. (2018). Model Pendidikan Kepramukaan Indonesia dalam Perspektif Filsafat Pendidikan Paulo Freire. Jurnal Filsafat, 28(2), 220-252.

lg channel. (2021, December 30). Big Brother Full Movie Subtitle Indonesia. https://www.youtube.com/watch?v=gffWHrdpgdI

Manullang, J., Maria, R., \& Manullang, A. (2021). Relevansi Pendidikan Humanis Paulo Freire Dengan Pendidikan Agama Kristen Jenjang Sekolah Menengah Atas. Jurnal Educatio FKIP UNMA, 7(2), 482 490.

Mualim, K. (2017). Gagasan pemikiran humanistik dalam pendidikan (perbandingan Pemikiran naquib al-attas dengan paulo freire). Al-Asasiyya: Journal Of Basic Education, 1(2).

Prastowo, A. I. (2020). Konsep Konsientisasi Paulo Freire Dan Relevansinya Terhadap Pendidikan Islam. Suhuf: Pengembangan Kajian Keislaman, 32(1), 13.

Prihartono, A. W., \& Sos, S. (2016). Surat Kabar \& Konvergensi Media (Studi Deskriptif Kualitatif Model Konvergensi Media Pada Solopos). Jurnal Channel, 4, 105-116.

Putra, I. K. R. (2021). Pendidikan Membebaskan Sebagai Upaya Mewujudkan Generasi Emas 2045 (Telaah Pemikiran Kritis Paulo Freire). Vidya Samhita: Jurnal Penelitian Agama, 6(1). 
Rohinah, R. (2019). Re-Konsientisasi dalam Dunia Pendidikan (Membangun Kesadaran Kritis Melalui Pemikiran Paulo Freire). Tarbiyah: Jurnal Ilmiah Kependidikan, 8(1), 1. https://doi.org/10.18592/tarbiyah.v8i1.2355

Rosikin, A. N. (2020, July 5). Film - Big Brother (2018) [..Com]. Tribunnewswiki. https://www.tribunnewswiki.com/2020/07/05/film-big-brother-2018

Sartika, E. (2014). Analisis isi kualitatif pesan moral dalam film berjudul "Kita versus Korupsi.” Jurnal Ilmu Komunikasi, 2(2), 63-77.

Sesfao, M. (2020). Perbandingan Pemikiran Pendidikan Paulo Freire Dengan Ajaran Tamansiswa Dalam Implementasi Merdeka Belajar. Implementasi Merdeka Belajar Berdasarkan Ajaran Tamansiswa, 1, 261-272. https://jurnal.ustjogja.ac.id/index.php/semnas2020/article/view/7604

Sholehuddin, S. (2018). Humanisasi Pendidikan; Meneguhkan Sisi Kemanusiaan dalam Proses Pembelajaran. Al-Afkar, Journal For Islamic Studies, 1(2, July), 73-87.

Suriadi, S. (2019). Etika Interaksi Edukatif Guru dan Siswa Menurut Perspektif Syaikh ‘Abd Al-Ṣamad AlFalimbānī. Dayah: Journal of Islamic Education, 1(2), 145. https://doi.org/10.22373/jie.v1i2.2928

Syaikhudin, A. (2012). Konsep pemikiran pendidikan menurut paulo freire dan ki hajar dewantoro. Cendekia: Jurnal Kependidikan Dan Kemasyarakatan, 10(1), 79-92.

Tahun, M. (2016, September 16). Gambaran "Guru Inovatif” [Go.id]. Kementrian Agama Kantor Wilayah Provinsi Nusa Tenggara Timur. https://ntt.kemenag.go.id/opini/94/gambaran-guru-inovatif

Tara, T. (2016). Mentalitas Peserta Didik, Pendidikan Transformatif Paulo Freire. Atma Reksa: Jurnal Pastoral Dan Kateketik, 1(1), 64-76.

Umar, U. (2014). Media Pendidikan: Peran dan Fungsinya dalam Pembelajaran. Tarbawiyah: Jurnal Ilmiah Pendidikan, 11(1), 131-144. https://doi.org/10.32332/tarbawiyah

Yuliani, W. (2018). Metode penelitian deskriptif kualitatif dalam perspektif bimbingan dan konseling. Quanta, 2(2), 83-91.

Zaini, M. (2014). Esensi Spirit Pendidikan Islam dalam Konsep Pemikiran Paulo Freire. El-Qudwah. 
FILM “BIG BROTHER 2018” SEBAGAI INOVASI RELASI GURU DAN SISWA PERSPEKTIF ...

Achmad Yulianto Widodo, Alaika M. Bagus Kurnia, Anugerah Ilma Dinilillahi, Moch. Wahyu Qodarullah 